\title{
Phenotype modifiers of spinal muscular atrophy: the number of SMN2 gene copies, deletion in the NAIP gene and probably gender influence the course of the disease
}

\author{
Maria Jędrzejowska ${ }^{1 凶}$, Michał Milewski², Janusz Zimowski ${ }^{3}$, Janina Borkowska ${ }^{1}$, \\ Anna Kostera-Pruszczyk ${ }^{4}$, Danuta Sielska ${ }^{2}$, Marta Jurek ${ }^{2}$ and \\ Irena Hausmanowa-Petrusewicz ${ }^{1}$ \\ ${ }^{1}$ Neuromuscular Unit, Mossakowski Medical Research Centre, Polish Academy of Sciences, Warszawa, Poland; \\ ${ }^{2}$ Department of Medical Genetics, National Research Institute of Mother and Child, Warszawa, Poland; \\ ${ }^{3}$ Department of Genetics, Institute of Psychiatry and Neurology, Warszawa, Poland; ${ }^{4}$ Department of Neurology, \\ Medical University of Warsaw, Warszawa, Poland
}

Received: 03 October, 2008; revised: 12 February, 2009; accepted: 11 March, 2009

available on-line: 14 March, 2009

\begin{abstract}
Spinal muscular atrophy (SMA) is an autosomal recessive neuromuscular disorder caused by mutations of the SMN1 gene. It is characterized by significant phenotype variability. In this study, we analyzed possible phenotype modifiers of the disease - the size of the deletion in the SMA region, the number of SMN2 gene copies, as well as the effect of gender. Among the factors analyzed, two seem to influence the SMA phenotype: the number of SMN2 gene copies and a deletion in the NAIP gene. A higher number of SMN2 copies makes the clinical symptoms more benign, and the NAIP gene deletion is associated with a more severe phenotype. The influence of gender remains unclear. In a group of 1039 patients, $55 \%$ of whom were male, the greatest disproportion was in the SMA1 $(F / M=0.78)$ and SMA3b $(F / M=0.45)$ forms. In SMA1 a deletion in the NAIP gene was seen twice as frequently in girls compared to boys. In three patients, we observed genotypes atypical for the chronic forms of SMA: two patients with SMA3a and $3 b$ had a deletion of the NAIP gene, and a third patient with SMA2 had one copy of the SMN2 gene.
\end{abstract}

Keywords: SMA modifiers, SMN2 gene copy number, NAIP deletion, gender influence

\section{INTRODUCTION}

Infantile and juvenile spinal muscular atrophy (SMA) is one of the most frequent autosomal recessive genetic disorders. The incidence of SMA is estimated at 1 per 5000 to 10000 births (Thieme et al., 1993; 1994). The disorder leads to a loss of lower motor neurons, resulting in muscle wasting and atrophy (Dubowitz, 1995). However, the age at the onset of the disease and the severity of clinical symptoms are highly variable. According to the International SMA Consortium, three clinical forms are distinguished: the severe form or Werdnig-Hoffmann disease (SMA1, children are never able to sit unaided), the intermediate form (SMA2, children sit but never walk) and the mild form or SMA3, in which weakness develops in patients who were previously able to walk unassisted (Munsat \& Davies, 1992). There are two subgroups in the third form - SMA3a (clinical symptoms before 3 years of age) and $3 b$ (onset between 3 and 20 years of age). This distinction is related to the observation that children in whom the disease manifests at the age of more than 3 years maintain their ability to walk unaided for a longer time (Zerres et al., 1997). The probability of maintaining the ability to walk unassisted after 10,20 and 40 years of the disease is $73 \%, 44 \%$ and $34 \%$, respectively, in SMA 3a, and $97 \%, 89 \%$ and

$\square$ Corresponding author: Maria Jędrzejowska, Neuromuscular Unit, Mossakowski Medical Research Centre, Polish Academy of Sciences, A. Pawińskiego 5, 02-106 Warszawa, Poland; tel./fax: (48) 22658 4501; e-mail address: mariaj@cmdik.pan. $\mathrm{pl}$ Abbreviations: NAIP, neuronal apoptosis inhibitor protein; SMA, spinal muscular atrophy; SMN1, survival of motor neuron 1; SMN2, survival of motor neuron 2. 
$67 \%$ in SMA 3b. Apart from these three basic clinical forms, two other forms have been described in the literature: an inborn form or SMA0 in which symptoms are already present in the foetus, and an adult form or SMA4, with variously defined age of onset (from 20 to 30 years) (Brahe et al., 1995, Zerres et al., 1995, Macleod et al., 1999; Dubowitz et al., 1999).

All the mentioned forms of spinal muscular atrophy are associated with mutations of the SMN1 gene, located in the SMA region (Lefebvre et al., 1995). This region is located on the long arm of chromosome 5 (5q12.3) and is composed of two similar segments - the centromeric and the telomeric one. The SMN1 gene is found in the telomeric segment, and its equivalent, the SMN2 gene, in the centromeric segment. In addition, there are several other genes in this region: NAIP, H4F5 and $p 44$, and many repeated sequences and pseudogenes, making it genetically unstable (Roy et al., 1995; Bürglen et al., 1997; Scharf et al., 1998). Over $95 \%$ of the mutations responsible for SMA are biallelic absence of exon 7 of the SMN1 gene (Lefebvre et al., 1995). Such a high homogeneity of the molecular basis is inconsistent with the phenotype variability of the disease and stimulated us to search for potential phenotype modifiers. Initially, the variability was thought to be linked to the size of the deletion in the SMA region (Lefebvre et al., 1995). It seemed that large deletions including neighboring genes such as NAIP might cause the severe form of the disease. This explanation was deemed probable as the NAIP gene belongs to a group of apoptosis inhibitors, so its damage might be involved in the loss of spinal motor neurons. Later on, phenotype variability began to be linked to the variable number and quality of $S M N$ genes (Burghes, 1997). SMN1 and SMN2 genes are bigeminally similar. Their sequences differ by five nucleotides, of which only the change in exon 7 is functionally significant. The SMN genes may undergo conversions, leading to formation of hybrid genes. Burghes (1997) proposed that the severe form of the disease might be caused by true deletions in the SMA region, and the mild form - by conversion of SMN forms. Since the SMN1 and NAIP deletions and the 1 or $2 S M N 2$ copies (an average number present in the population) are mostly seen in the severe form, this is an evidence of a true deletion including the entire telomeric section of the SMA region, with the centromeric part remaining intact. In turn, the 3 or 4 SMN2 copies present in patients with the mild form of the disease probably result from the conversion of SMN1 into SMN2. In line with this, studies regarding phenotype modifiers concentrated solely on the number of SMN2 copies. A strong correlation was shown between the number of SMN2 copies and the disease phenotype. Patients with the severe form usually have 1 or 2 copies, those with the intermediate form have 2 or 3 copies, and those with the mild form have 3-4 or even 5 or 6 copies (Feldkötter et al., 2002; Mailman et al., 2002; Yamashita et al., 2004). However, the influence of the number of SMN2 copies is not implicit, e.g. three SMN2 copies have been observed in both SMA1 and SMA3. Probably the SMN2 copies are not functionally equivalent and produce various amounts of a fully functional SMN protein (Harada et al., 2004).

Apart from the evident influence of the differences in the SMA region on the phenotype, the effect of gender on the disease phenotype has also been noted in the literature. It has been observed that women compared to men are half as often affected with the mild form and the protective effect of estrogens has been suggested (HausmanowaPetrusewicz et al., 1984). In addition, cases of asymptomatic biallelic mutation of the SMN1 gene occur more frequently in women than in men (Helmken et al., 2003).

Despite many studies on the phenotype variability, to date no simultaneous analysis of all putative phenotype modifiers mentioned above has been carried out. Indeed, any effect of the size of the deletion in the SMA region has been negated. The effect of gender also remains unclear. Therefore, we decided to carry out a simultaneous analysis of the size of deletion of the SMA region, the number of SMN2 copies and the effect of gender on the SMA phenotype.

\section{PATIENTS AND METHODS}

Gender analysis was performed in a group of 1039 patients diagnosed in our centers, which included 204 cases with SMA1 (114 males (M), 90 females (F)), 330 - with SMA2 (171M, 159F), 298 - with SMA3a (142M, 156F), 206 - with SMA3b $(142 \mathrm{M}, 64 \mathrm{~F})$ and one female with SMA4 (disease onset at the age of 34 years). Extended molecular studies were carried out in a group of 240 patients, including 86 patients with SMA1 $(38 \mathrm{~F}, 48 \mathrm{M}), 68$ with SMA2 (26F, 42M), 48 with SMA3a (21F, 27M), 37 with SMA3b (13F, 24M) and 1 patient (F) with SMA4. Molecular studies included analysis of the size of the deletion in the SMA region (presence of a deletion of exons 7 and 8 of the SMN1 gene and exons 5 and 6 of the NAIP gene) and the number of SMN2 copies.

Genomic DNA was collected from the peripheral blood of SMA patients. DNA was isolated from blood samples by salting-out procedure (Miller et al., 1988). Homozygous absence of exons 7 and 8 of SMN1 was detected using restriction analysis, as described elsewhere (Scheffer et al., 2001). Deletion 
of the NAIP gene was analyzed using exon 5 and 13 primers as previously described (Roy et al., 1995). For SMN1 and SMN2 dosage analysis, the method described by Anhuf et al. (2003) was employed with some modification (Jędrzejowska et al., 2008).

Statistical analysis was performed using multifactorial logistic regression analysis with step-wise strategy of factor selection, log-linear models, and Fisher exact statistics (Armitage, 2002). Correlations between variables were measured using Spearman coefficients.

\section{RESULTS}

Size of the deletion in the SMA region

In the study group of 240 patients, a large deletion including the NAIP gene was found in 48 patients, an isolated loss of exon 7 of the SMN1 gene in 38 patients, and in the remaining 154 patients a deletion of exons 7 and 8 of SMN1 was found, with the NAIP gene intact (Table 1).

The deletion in the NAIP gene correlated with the severity of clinical symptoms (Fisher's exact test, $P<0.0001)$. The NAIP gene was absent in the majority $(73 \%)$ of patients with the severe form. In the mild form ( $3 a$ and $3 b$ ), only two such deletions were found (described in the following section). On the other hand, an isolated absence of exon 7 was seen with a similar frequency in all forms of SMA.

\section{Number of copies of the SMN2 gene}

The presence of one copy of the SMN2 gene was shown in 4 patients $(1.67 \%)$ in the studied group, of two copies in 50 patients $(20.83 \%)$, three copies in 131 patients $(54.58 \%)$, four copies in 53 patients $(22.08 \%)$ and five copies of the gene in two patients $(0.83 \%)$ (Tables 1 and 2$)$.

The number of SMN2 gene copies correlated with the phenotype of the disease. The greater the number of SMN2 copies, the more benign was the phenotype (Spearman's correlation coefficient $r=0.74$, $P<0.05)$. In the severe form, one or two SMN2 copies (59\% patients) were most frequently seen, but three copies of the gene $(41 \%)$ were also quite frequent. In SMA2, $84 \%$ of patients had three copies of the gene. In SMA3a, three or four SMN2 copies were seen (in $66 \%$ and $33 \%$ patients, respectively). In SMA 3b, four SMN2 copies $(78 \%)$ were most frequently seen. In one patient with SMA2 (the case is described below), the presence of one SMN2 copy was demonstrated.

\section{Gender of patients}

Overall, male patients with SMA outnumbered female patients (470F vs. 569M). This was particularly true for the benign form with the onset at the age of over 3 years $(64 \mathrm{~F}$ vs. $142 \mathrm{M}, P<0.0001)$ as well as the severe form - SMA1 (90F vs. $114 \mathrm{M})$ $(P=0.0042$, compared to the proportion in the gener-

Table 1. Number of SMN2 gene copies and the size of deletion in SMA region in particular types of SMA by gender.

The disease phenotype correlated with the number of SMN2 copies and the deletion of the NAIP gene. When gender proportions were taken into account in particular forms, we found a higher percentage of girls with the severe form, two SMN2 copies and a deletion including the NAIP gene. M, male; F, female.

\begin{tabular}{|c|c|c|c|c|c|c|c|c|}
\hline \multirow{2}{*}{$\begin{array}{l}\text { Type of } \\
\text { SMA }\end{array}$} & \multirow{2}{*}{$\begin{array}{l}\text { Size of } \\
\text { deletion }\end{array}$} & \multicolumn{5}{|c|}{ Number of SMN2 gene copies } & \multirow[t]{2}{*}{ Overall } & \\
\hline & & 1 & 2 & 3 & 4 & 5 & & \\
\hline \multirow[t]{3}{*}{ SMA1 } & NAIP & $2(2 \mathrm{M})$ & $27(18 \mathrm{~F}, 9 \mathrm{M})$ & $6(3 \mathrm{~F}, 3 \mathrm{M})$ & 0 & 0 & $35(21 \mathrm{~F}, 14 \mathrm{M})$ & $86(38 \mathrm{~F}, 48 \mathrm{M})$ \\
\hline & $\begin{array}{l}\text { Exons } 7 \\
\text { and } 8\end{array}$ & $1(1 \mathrm{~F})$ & $18(8 \mathrm{~F}, 9 \mathrm{M})$ & $24(7 \mathrm{~F}, 17 \mathrm{M})$ & 0 & 0 & $42(16 \mathrm{~F}, 26 \mathrm{M})$ & \\
\hline & Exon 7 & 0 & $3(3 \mathrm{M})$ & $6(1 \mathrm{~F}, 5 \mathrm{M})$ & 0 & 0 & $9(1 \mathrm{~F}, 8 \mathrm{M})$ & \\
\hline \multirow[t]{3}{*}{ SMA2 } & NAIP & 0 & $2(2 \mathrm{M})$ & $9(2 \mathrm{~F}, 7 \mathrm{M})$ & 0 & 0 & $11(2 \mathrm{~F}, 9 \mathrm{M})$ & $68(26 \mathrm{~F}, 42 \mathrm{M})$ \\
\hline & $\begin{array}{l}\text { Exons } 7 \\
\text { and } 8\end{array}$ & $1(1 \mathrm{M})$ & 0 & $38(15 \mathrm{~F}, 23 \mathrm{M})$ & $4(2 \mathrm{~F}, 2 \mathrm{M})$ & 0 & $43(17 \mathrm{~F}, 26 \mathrm{M})$ & \\
\hline & Exon 7 & 0 & $1(1 \mathrm{~F})$ & $10(4 \mathrm{~F}, 6 \mathrm{M})$ & $3(2 \mathrm{~F}, 1 \mathrm{M})$ & 0 & $14(7 \mathrm{~F}, 7 \mathrm{M})$ & \\
\hline \multirow[t]{3}{*}{ SMA3a } & NAIP & 0 & 0 & $1(1 \mathrm{M})$ & 0 & 0 & $1(1 \mathrm{M})$ & $48(21 \mathrm{~F}, 27 \mathrm{M})$ \\
\hline & $\begin{array}{l}\text { Exons } 7 \\
\text { and } 8\end{array}$ & 0 & 0 & $24(13 \mathrm{~F}, 11 \mathrm{M})$ & $13(4 \mathrm{~F}, 9 \mathrm{M})$ & 0 & 37 (17F, 20M) & \\
\hline & Exon 7 & 0 & 0 & $7(4 \mathrm{~F}, 3 \mathrm{M})$ & $3(3 \mathrm{M})$ & 0 & $10(4 \mathrm{~F}, 6 \mathrm{M})$ & \\
\hline \multirow[t]{3}{*}{ SMA3b } & NAIP & 0 & 0 & 0 & $1(1 \mathrm{M})$ & 0 & $1(1 \mathrm{M})$ & $37(13 \mathrm{~F}, 24 \mathrm{M})$ \\
\hline & $\begin{array}{l}\text { Exons } 7 \\
\text { and } 8\end{array}$ & 0 & 0 & $6(3 \mathrm{~F}, 3 \mathrm{M})$ & $23(7 \mathrm{~F}, 16 \mathrm{M})$ & $2(2 F)$ & $31(12 \mathrm{~F}, 19 \mathrm{M})$ & \\
\hline & Exon 7 & 0 & 0 & 0 & $5(1 \mathrm{~F}, 4 \mathrm{M})$ & 0 & $5(1 \mathrm{~F}, 4 \mathrm{M})$ & \\
\hline SMA4 & $\begin{array}{l}\text { Exon } 7 \\
\text { and } 8\end{array}$ & 0 & 0 & 0 & $1(1 \mathrm{~F})$ & 0 & $1(1 \mathrm{~F})$ & $1(1 \mathrm{~F})$ \\
\hline Overall & & $4(1 \mathrm{~F}, 3 \mathrm{M})$ & $50(27 \mathrm{~F}, 23 \mathrm{M})$ & $131(52 \mathrm{~F}, 79 \mathrm{M})$ & $53(17 \mathrm{~F}, 36 \mathrm{M})$ & $2(2 \mathrm{~F})$ & $240(99 \mathrm{~F}, 141 \mathrm{M})$ & \\
\hline
\end{tabular}


al population at the age of $0-14$ years). The ratio of females to males in the whole study group (1039 patients) was $\mathrm{F} / \mathrm{M}=0.82$, and for SMA1, SMA2, SMA3a and SMA3b the $\mathrm{F} / \mathrm{M}$ ratio was $0.78,0.92,1.1$ and 0.45 , respectively.

Table 2. Number of SMN2 gene copies in the study group

\begin{tabular}{lclllll}
\hline \multicolumn{7}{c}{ Analysis Variable : st_SMN2 } \\
\hline SMN2 copies & N obs. & Mean & Std. Dev.* & Median & Minimum & Maximum \\
\hline 1 & 4 & 1.0058 & 0.1295 & 0.9960 & 0.8600 & 1.1710 \\
2 & 50 & 2.0468 & 0.1284 & 2.0590 & 1.7240 & 2.2530 \\
3 & 131 & 2.9949 & 0.1569 & 3.0150 & 2.7020 & 3.2560 \\
4 & 53 & 3.9425 & 0.1307 & 3.9590 & 3.6340 & 4.1660 \\
5 & 2 & 4.9180 & 0.1782 & 4.9180 & 4.7920 & 5.0440 \\
\hline
\end{tabular}

*Std. Dev., Standard deviation.

Correlation analysis between the size of the deletion and the number of SMN2 copies in various types for each gender separately did not show significant differences between male and female sex (in log-linear models). However, in the group with SMA1 there were more girls with a deletion in the NAIP gene $(21 / 38,55 \%)$ compared to boys $(14 / 48$, $29 \%$ ). Also, more girls had two SMN2 copies (26/38, $68 \%$ ) compared to boys $(21 / 48,43 \%)$. Of particular note was the greater number of girls in the group with the NAIP deletion and two SMN2 copies ( $47.3 \%$ girls vs. $18.7 \%$ boys with SMA1). In the remaining groups, particular sizes of the deletion and the number of SMN2 copies occurred with similar frequency both in men and women, giving rise to a similar phenotype.

Multifactorial logistic regression analysis with step-wise factor selection (number of SMN2 copies, presence of a deletion of exons 7 and 8, isolated deletion of exon 7, deletion of exon 7 and 8 SMN1 and NAIP, gender of patients) carried out in the group of 240 patients showed an independent significant effect of two factors on the SMA phenotype - NAIP gene deletion $(P=0.0022)$ and the number of SMN2 copies $(P<0.0001)$.

\section{Cases with a genotype atypical for chronic form}

In the studied cohort, we identified several patients who differed from the usually observed correlation, including two patients with the mild form and a deletion of the NAIP gene and one patient with SMA2 and one copy of the SMN2 gene. A short description of these cases is presented below:

1. A boy born in 2000, SMA3a. He was born following a first, uneventful pregnancy. Initial symptoms occurred in the second year of life. These included difficulties in walking that were seen already at the outset of that developmental stage and frequent falls. The patient never became able to run. When examined at 5 years of age, he sat and walked unaided, his gait was rolling, and he stood up from squatting with assistance. Molecular studies showed the presence of a large deletion, also including the NAIP gene, and three SMN2 copies. The level of SMN protein in skin fibroblasts measured by the Western blotting was $97.7 \%$ of normal.

2. A man born in 1952, SMA3b, first symptoms at around 14 years of age, including difficulty in climbing stairs, walking, and hand tremor. When last examined at the age of 48 years, the patient sat and walked unaided (albeit with slightly rolling gait), could stand up from the sitting position with assistance, but was unable to stand up from squatting. Genetic studies showed deletion of SMN1 and NAIP genes and four SMN2 copies.

3. A boy born in 1999, SMA2/3a. He was born following a second pregnancy which was complicated by frequent uterine contractions. At birth he presented flaccidity. At 6 months of age, the boy sat when put in position and crawled. He never sat unaided, did not stand up from squatting, but stood with assistance when positioned to standing. He started walking with assistance at around 15 months. He could never climb stairs or run. Genetic examination showed a deletion of exons 7 and 8 of the SMN1 gene, while the NAIP gene was remained intact and there was one SMN2 copy.

\section{DISCUSSION}

Our study is the first reported evaluation of the patients' gender impact on the SMA phenotype and analysis of its correlation with two critical molecular factors: the copy number of the SMN2 gene and the deletion status of the NAIP gene.

Of the several factors considered as SMA phenotype modifiers, two seem to have an influence - the number of SMN2 gene copies and the deletion of the NAIP gene. The effect of the number of SMN2 gene copies seems to be quite evident. Similar to previous studies, the correlation between the number of SMN2 gene copies and the phenotype was robust. Of note, the low percentage of patients with only one copy of the SMN2 gene (4/240) is consistent with the results of previous studies (9/375 in a study by Feldkötter, and 7/142 in a study by Mailman) (Feldkötter et al., 2002; Mailman et al., 2002). The loss of both SMN1 alleles in the presence of only one SMN2 copy may thus be a lethal characteristic. 
One of our most important observations is that the presence of a deletion in the NAIP gene worsens the prognosis independently of the number of SMN2 copies. Although the deletion of NAIP probably only indicates the mechanism of loss of $S M N 1$, it is an independent prognostic factor. As we observed three copies of the SMN2 gene in all phenotypes $(41.86 \%$ in SMA1; $83.82 \%$ in SMA2; $66.43 \%$ in SMA3a, and $16.22 \%$ in SMA3b), the NAIP gene deletion and three SMN2 copies was found only in SMA1 and 2 (with one exception).

The issue of the influence of gender has been briefly mentioned in the literature on spinal muscular atrophy but has never been fully explained. The phenomenon of half as many girls over the age of 8 years being affected by SMA compared to boys at the same age has been observed for many years (HausmanowaPetrusewicz et al., 1984). The reverse gender proportions occur among asymptomatic carriers of biallelic deletions, where women predominate (14 vs. 9 in our data, and 13 vs. 5 when only siblings were taken into account) (Cobben et al., 1995; Hahnen et al., 1995; Capon et al., 1996; Wang et al., 1996; Bussaglia et al., 1997; Helmken et al., 2003; Prior et al., 2004; Cuscó et al., 2006; Jędrzejowska et al., 2008). In our study group, the predominance of the male gender was noticeable, being the most strongly represented in the mild form $3 b$, which is in line with previous observations. However, molecular studies of the SMA region in this group did not show any significant differences depending on gender, indicating the presence of an independent phenotype modifier. Thus, it seems that the lower frequency of girls affected with the mild form is not associated with differences in the molecular basis of the SMA region and requires further investigation.

We also observed a great disproportion between females and males in the severe SMA1 form. However, the differences in this group also included the molecular basis of the disease. The more severe genotype (NAIP gene deletion and the presence of two SMN2 copies) was observed three times as often in girls $(47.3 \%(18 / 38)$ in F vs. $18.7 \%$ (9/48) in M). In SMA1, Novelli et al. (1997) found a higher percentage of girls with the NAIP gene deletion $(75.6 \%)$ compared to boys $(52.5 \%)$. In his opinion the presence of the NAIP gene might be essential to initiate a protective factor dependent on gender. Lack of the NAIP gene would inhibit this factor and thus increase the percentage of girls with the severe form in the group with a deletion of the NAIP gene. If this hypothesis is true, we should expect a lower percentage of females with NAIP in the chronic forms, but this was not seen in the group studied by Novelli. In our group, very few patients with the chronic form had the NAIP gene deletion, but a large majority of them were boys (11 vs 2). Thus, our data would seem to be concordant with the hypothesis put forward by Novelli.
In our study group, we identified three cases of the chronic form with an atypical genotype: two patients with the mild form of SMA and a deletion including NAIP gene and one boy with a borderline form 2/3a and one SMN1 copy. A deletion in the mild form of the disease is rare, although it has already been reported in the literature (Yamashita et al., 2004). If we assume that the NAIP gene deletion only indicates the genetic mechanism of the absence of the SMN1 gene, i.e. a true deletion, then the question arises how the presence of 3 or 4 SMN2 copies could be explained. One can speculate that a deletion involved an allele that initially underwent a conversion of the SMN1 genes into SMN2. Taking into account the instability of the SMA region, such a sequence of events seems feasible. We found the presence of only one copy of the SMN2 gene in a patient with the intermediate form more surprising. In a large study of the correlation between the number of SMN2 gene copies and the phenotype, Feldkötter found that the presence of one copy of this gene was unconditionally associated with the severe form. In addition, the maximum lifespan of such patients was 11 months (Feldkötter et al., 2002). Also in the study by Mailman et al. (2002), the presence of one copy was closely linked with the severe form. Only Burghes (1997) observed several patients (seven) with the intermediate and mild form and only one SMN2 copy.

Our study indicates that despite progress in the understanding of the phenotype-genotype correlations in spinal muscular atrophy, there is a number of issues that still need to be clarified. The effect of gender that seems to be significant but still unclear is the most controversial. Our data show that many factors can change the phenotype and much more needs to be explained by examining the phenotype-genotype correlations. Nevertheless, when assessing the prognosis in spinal muscular atrophy, two characteristics should be borne in mind, namely the number of SMN2 gene copies and the presence of a deletion in the NAIP gene.

\section{Acknowledgements}

This study was supported by grants from the State Committee for Scientific Research No. 2P05E 00727 (to M.J.) and the Foundation to Support the Development of Polish Pharmacy and Medicine No. II/201/2003 (to I.H.P.).

\section{REFERENCES}

Anhuf D, Eggermann T, Rudnik-Schöneborn S, Zerres K (2003) Determination of SMN1 and SMN2 copy number using TaqMan Technology. Hum Mutat 22: 74-78.

Armitage P, Berry G, Matthews JNS (2002) Statistical Methods in Medical Research. 4th edn, Blackwell Science Ltd.

Brahe C, Servidei S, Zappata S, Ricci E, Tonali P, Neri G (1995) Genetic homogeneity between childhood-onset 
and adult-onset autosomal recessive spinal muscular atrophy. Lancet 346: 741-742.

Burghes AH (1997) When is a deletion not a deletion? When it is converted? Am J Hum Genet 61: 9-15.

Bürglen L, Seroz T, Miniou P, Lefebvre S, Burlet P, Munnich A, Pequignot EV, Egly JM, Melki J (1997) The gene encoding $\mathrm{p} 44$, a subunit of the transcription factor TFFIH, is involved in large scale deletion associated with Werdnig-Hoffmann disease. Am J Hum Genet 60: 72-79.

Bussaglia E, Tizzano EF, Illa I, Cervera C, Baiget M (1997) Cramps and minimal EMG abnormalities as preclinical manifestation of spinal muscular atrophy patients with homozygous deletions of the SMN gene. Neurology 48: 1443-1445.

Capon F, Levato C, Merlini L, Angelini C, Mostacciuolo ML, Politano L, Novelli G, Dallapicola B (1996) Discordant clinical outcome in type III spinal muscular atrophy sibships showing the same deletion pattern. Neuromusc Disord 6: 261-264.

Cobben JM, Van der Steege G, Grootscholten P, De Visser M, Scheffer H, Buys CHCM (1995) Deletions of the survival motor neuron gene in unaffected siblings of patients with spinal muscular atrophy. Am J Hum Genet 57: 805-808.

Cuscó I, Barceló MJ, Rojas-García R, Illa I, Gamez J, Cervera $C$, Pou A, Izquierdo $G$, Baiget $M$, Tizzano EF (2006) SMN2 copy number predicts acute or chronic spinal muscular atrophy but does not account for intrafamilial variability in siblings. J Neurol 253: 21-25.

Dubowitz V (1995) Disorders of lower motor neurone: the spinal muscular atrophies. In Muscle Disorders in Childhood, Dubowitz V, ed. Saunders, London.

Dubowitz V (1999) Very severe spinal muscular atrophy (SMA type 0): an expanding clinical phenotype. Eur J Paediatr Neurol 3: 49-51.

Feldkötter M, Schwarzer V, Wirth R, Wienker TF, Wirth B (2002) Quantitative analysis of SMN1 and SMN2 based on real-time Light Cycler PCR: Fast and highly reliable carrier testing and prediction of severity of spinal muscular atrophy. Am J Hum Genet 70: 358-368.

Hahnen E, Forkert R, Marke Ch, Rudnik-Schöneborn S, Schönling J, Zerres K, Wirth B (1995) Molecular analysis of candidate genes on chromosome 5 q13 in autosomal recessive spinal muscular atrophy: evidence of homozygous deletions of the SMN gene in unaffected individuals. Hum Mol Genet 4: 1927-1933.

Harada Y, Sutomo R, Sadewa AH, Akutsu T, Takeshima Y, Wada H, Matsuo M, Nishio H (2004) Correlation between SMN2 copy number and clinical phenotype of spinal muscular atrophy: three SMN2 copies fail to rescue some patients from disease severity. J Neurol 249: 1211-1219.

Hausmanowa-Petrusewicz I, Zaremba J, Borkowska J, Szirkowiec W (1984) Chronic proximal spinal muscular atrophy of childhood and adolescence: sex influence. J Med Genet 21: 447-450.

Helmken C, Hofmann Y, Schoenen F, Oprea G, Raschke H, Rudnik-Schöneborn S, Zerres K, Wirth B (2003) Evidence for modifying pathway in SMA discordant families: reduced SMN level decreases the amount of its interacting partners and Htra2-beta1. Hum Genet 114: $11-21$.

Jędrzejowska M, Borkowska J, Zimowski J, Kostera-Pruszczyk A, Milewski M, Jurek M, Sielska D, Kostyk E, Nyka W, Zaremba J, Hausmanowa-Petrusewicz I (2008) Unaffected patients with a homozygous absence of the SMN1 gene. Eur J Hum Genet 16: 930-9344.
Lefebvre S, Burglen L, Roboullet S, Clermont O, Burlet $\mathrm{P}$, Viollet L, Benichou B, Cruaud C, Millasseau P, Zeviani $M$ et al. (1995) Identification and characterization of spinal muscular atrophy determining gene. Cell $\mathbf{8 0}$ : 155-165.

Macleod MJ, Taylor JE, Lunt PW, Mathew ChG, Robb SA. (1999) Prenatal onset spinal muscular atrophy. Eur J Paediatr Neurol 3: 65-72.

Mailman MD, Heinz JW, Papp AC, Snyder PJ, Sedra MS, Wirth B, Burghes AH, Prior TW (2002) Molecular analysis of spinal muscular atrophy and modification of the phenotype by SMN2. Genet Med 4: 20-26.

Miller SA, Dykes DD, Poleski HF (1988) A simple salting out procedure for extracting DNA from human nucleated cells. Nucleic Acids Res 16: 1215.

Munsat T, Davies K (1992) Report of International SMA Consortium Meeting. Neuromusc Disord 2: 423-428.

Novelli G, Semprini S, Capon F, Dallapiccola B (1997) A possible role of NAIP gene deletions in sex-related spinal muscular atrophy phenotype variation. Neurogenetics 1: 29-30.

Prior TW, Swoboda KJ, Scott HD, Hejmanowski AQ (2004) Homozygous SMN1 deletions in unaffected family members and modification of the phenotype by SMN2. Am J Med Genet 130A: 307-310.

Roy N, Mahadevan MS, McLean M, Shutler G, Yaraghi Z, Frahani R, Baird S, Besner-Johnston A, Lefevre C, Kang $X$ et al. (1995) The gene for neuronal apoptosis inhibitor protein is partially deleted in individuals with spinal muscular atrophy. Cell 80: 167-178.

Scharf JM, Endrizzi MG, Wetter A, Huang S, Thompson TG, Zerres K, Dietrich WF, Wirth B, Kunkel LM (1998) Identification of a candidate modifying gene for spinal muscular atrophy by comparative genomics. Nat Genet 20: 83-86.

Scheffer H, Cobben JM, Matthijs G, Wirth B (2001) Best practice guidelines for molecular analysis in spinal muscular atrophy. Eur J Hum Genet 9: 484-491.

Thieme A, Mitulla B, Schulze F, Spiegler AW (1993) Epidemiological data on Werdnig-Hoffmann disease in Germany (West-Thuringen). Hum Genet 91: 295-297.

Thieme A, Mitulla B, Schulze F, Spiegler AW (1994) Chronic childhood spinal muscular atrophy in Germany (West-Thuringen) - an epidemiological study. Hum Genet 93: 344-346.

Wang $\mathrm{CH}, \mathrm{Xu}$ J, Carter TA, Ross BM, Dominski MK, Bellcross CA, Penchaszadeh GK, Munsat TL, Gilliam TC (1996) Characterization of survival motor neuron $\left(\mathrm{SMN}^{\mathrm{T}}\right)$ gene deletions in asymptomatic carriers of spinal muscular atrophy. Hum Mol Genet 5: 359-365.

Wirth B, Brichta L, Schrank B, Lochmüler H, Blick S, Baasner A, Heller R (2006) Mildly affected patients with spinal muscular atrophy are partially protected by an increased SMN2 copy number. Hum Genet 119: 422-428.

Yamashita M, Nishio H, Harada Y, Matsuo M, Yamamoto $\mathrm{T}$ (2004) Significant increase in the number of the SMN2 gene copies in an adult-onset type III spinal muscular atrophy patient with homozygous deletion of the NAIP gene. J Neurol 52: 101-106.

Zerres K, Rudnik-Schöneborn S, Forrest E, Łusakowska A, Borkowska J, Hausmanowa-Petrusewicz I (1997) A collaborative study on the natural history of childhood and juvenile onset proximal spinal muscular atrophy (type II and III): 569 patients. J Neurol Sci 146: 67-72.

Zerres K, Rudnik-Schöneborn S, Forkert R, Wirth B (1995) Genetic bases of adult onset spinal muscular atrophy. Lancet 346: 1162. 